\title{
Effect of Chain End Group-Substrate Interaction on Surface Molecular Motion of Polystyrene Ultrathin Films
}

\author{
EL Sayed Ahmed Mounir, Atsushi TaKahara, and Tisato KaJIYAma ${ }^{\dagger}$
}

\author{
Department of Materials Physics and Chemistry, \\ Graduate School of Engineering, Kyushu University, \\ 6-10-1 Hakozaki, Higashi-ku, Fukouka 812-8581, Japan
}

(Received January 27, 1999)

\begin{abstract}
Surface molecular motions of monodisperse proton-terminated polystyrene (PS-H), monocarboxyl-terminated PS (PSCOOH) and dicarboxyl-terminated PS $\left(\alpha, \omega-\mathrm{PS}(\mathrm{COOH})_{2}\right)$ ultrathin films were investigated on the basis of lateral force microscopic (LFM) measurement at $293 \mathrm{~K}$, as a function of number-average molecular weight, $M_{n}$, and chain end functionality. In the case of the PS-H thin films with $M_{n}=19.7 \mathrm{k}$ and $40.4 \mathrm{k}$ spin-coated onto Si-wafer, the surface molecular motion was activated in a glass-rubber transition state at $293 \mathrm{~K}$ due to the excess free volume induced by a surface localization of chain end groups. Also, in the cases of the PSCOOH $\left(M_{n}=9.7 \mathrm{k}, 45.9 \mathrm{k}\right)$ and the $\alpha, \omega-\mathrm{PS}(\mathrm{COOH})_{2}\left(M_{n}=12.0 \mathrm{k}, 51.7 \mathrm{k}\right)$ ultrathin films spin-coated onto Si-wafer and their annealed ones at $393 \mathrm{~K}$ for $8 \mathrm{~h}$, the surface molecular motion was also enhanced even at room temperature due to a weak ionic interaction between $\mathrm{Si}-\mathrm{OH}$ of substrate and $-\mathrm{COOH}$ end group. On the other hand, the PSCOOH $\left(M_{n}=9.7 \mathrm{k}, 45.9 \mathrm{k}\right)$, and the $\alpha, \omega-\mathrm{PS}(\mathrm{COOH})_{2}\left(M_{n}=12.0 \mathrm{k}, 51.7 \mathrm{k}\right)$ spin-coated ultrathin films onto aminosilane-treated $\mathrm{Si}$-wafer did not show any distinct activation of surface mobility owing to a specific interaction between $\mathrm{NH}_{2}$-group of aminosilane-treated Si-wafer and - $\mathrm{COOH}$ end group of PS, being independent of annealing temperature, $M_{n}$ and functionality.

KEY WORDS Proton-Terminated Polystyrene / Monocarboxyl-Terminated Polystyrene / DicarboxylTerminated Polystyrene / Lateral Force Microscopy / Surface Molecular Motion / Aminosilane-Treated Si-Wafer /
\end{abstract}

Fundamental understandings on the surface and interfacial physical properties of amorphous polymer films are important for many functional applications, such as permselective membranes, lubricating, coatings, adhesives and microelectronics encapsulants. ${ }^{1,2}$

The nature of the glass transition behavior and surface molecular motion of end-functionalized polymers is still imperfectly understood in the case of ultrathin films. ${ }^{3}$ Recently, the studies on thermal molecular motions in the polymeric thin films ${ }^{4-6}$ and at the polymeric solid surfaces ${ }^{7-9}$ have been progressed due to the technological importance as well as the scientific interests.

The authors have investigated surface molecular motions of monodisperse and polydisperse polystyrene (PS) films by using scanning viscoelasticity microscopic (SVM) and lateral force microscopic (LFM) techniques. ${ }^{10-12}$ In the case of the monodisperse PS film with $M_{n}$ smaller than $c a$. $30 \mathrm{k}$, the film surface was in a glass-rubber transition or in a rubbery state even at room temperature due to a preferential surface localization of hydrophobic chain end groups. On the other hand, in the case of commercially available polydisperse PS film with polar chain ends, no remarkable activation of the surface molecular motions was observed at $293 \mathrm{~K}$ due to a depletion of chain ends from the surface even in the case of $M_{n}$ smaller than $c a$. 30k.

Since a little information has been known about the effects of polymer molecular weight, chain end groupsubstrate interaction and annealing treatment on the surface molecular motion of end-functionalized polymer ultrathin films, it is necessary to address this problem on the basis of lateral force microscopic measurement of polymer ultrathin films as a function of number-

\footnotetext{
To whom correspondence should be addressed.
}

average molecular weight $\left(M_{n}\right)$, the annealing temperature and the chain end functionality. LFM is a useful tool for the two dimensional measurements of lateral force which is evaluated by detecting the torsion of the sliding cantiliever. ${ }^{13,14}$ Since the frictional force is closely related to the surface relaxation behavior of polymeric materials, ${ }^{15,16}$ it becomes possible to investigate surface molecular motion on the basis of the scanning rate dependence of lateral force. ${ }^{17}$

As mentioned in our previous paper, ${ }^{18}$ the dewetting of end-functionalized PS spin-coated onto Si-wafer were observed in the cases that annealing temperature increased and the polymer solution concentration decreased, while those polymers spin-coated onto aminosilane-treated Si-wafer, did not show any dewetting structure being independent of the annealing temperature, the chain end functionality and polymer solution concentration (thickness).

The purpose of this study is to investigate the surface molecular motion of end-functionalized PS ultrathin films as a function of surface chemistry of substrate, number-average $M_{n}$, annealing temperature and chain end functionality, based on lateral force microscopy (LFM).

\section{EXPERIMENTAL}

\section{Materials}

Polymers used in this study were proton-terminated polystyrene (PS-H. $M_{n}=19.7 \mathrm{k}, M_{w} / M_{n}=1.08$ and $M_{n}$ $\left.40.4 \mathrm{k}, M_{w} / M_{n}=1.08\right)$, monocarboxyl-terminated polystyrene (PSCOOH. $M_{n}=9.7 \mathrm{k}, M_{w} / M_{n}=1.18, f=0.98$ and $\left.M_{n} 45.9 \mathrm{k}, M_{w} / M_{n}=1.05, f=0.96\right)$ and dicarboxylterminated polystyrenes $\left(\alpha, \omega-\operatorname{PS}(\mathrm{COOH})_{2} . M_{n}=12.0 \mathrm{k}\right.$, $M_{w} / M_{n}=1.09, f=1.98$ and $M_{n}=51.7 \mathrm{k}, M_{w} / M_{n}=1.08$, 
$f=1.95$ ), where $M_{n}$ is number-average molecular weight and $M_{w} / M_{n}$ is the degree of polydispersity, and $f$ is a functionality of end-functionalized PS. Monodisperse poystyrenes (PS-H) were synthesized by a living anionic polymerization with $s$-butyllithium as an anionic monofunctional initiator and methanol as a terminating agent. The PSCOOH and the $\alpha, \omega-\mathrm{PS}(\mathrm{COOH})_{2}$ were purchased from Polymer Source Inc.

\section{Film Preparation}

Polymer thin films were prepared by spin-coating a $0.5 \mathrm{wt} \%$ of polymer solution in toluene onto different substrate at $2500 \mathrm{rpm}$. Substrates used in this study were native oxide Si-wafer and aminosilane-treated Si-wafer. Aminosilanization was carried out by chemisorption of 4-aminobutyl-monomethoxydimethylsilane (ABDMS) on a dried clean Si-wafer. ${ }^{19}$ The substrate was placed on a teflon holder that was fixed in a round glass reactor and $0.2 \mathrm{ml}$ of $\mathrm{ABDMS}$ was dropped into a glass reactor by syringe. Then the glass reactor was evacuated to $20 \mathrm{mmHg}$ and heated to $373 \mathrm{~K}$ for $2 \mathrm{~h}$. Since ABDMS was evaporated, aminosilanization of Si-wafer was carried out in a gas phase. The aminosilane-treated Siwafer was rinsed with chloroform to remove unbound ABDMS. The aminosilanization in a vapor state formed a homogeneous and flat monolayer on the Si-wafer.

\section{Characterization of the Films}

The bulk glass transition temperatures, $T_{\mathrm{g}}$ 's of the $\mathrm{PS}-\mathrm{H}$, the PSCOOH, and the $\alpha, \omega$-PS $(\mathrm{COOH})_{2}$ samples were measured with differential scanning calorimetry (DSC 3200, MAC Science Co., Ltd.) at a heating rate of $10 \mathrm{~K} \mathrm{~min}^{-1}$ under nitrogen atmosphere.

FT-IR-ERS spectra were obtained by Nicolet a MAGNA-IR, 860 spectrometer. The spectra of the dicarboxyl-terminated PS films were recorded by making 516 scans in a $1400-1800 \mathrm{~cm}^{-1}$ with a resolution of $4 \mathrm{~cm}^{-1}$ by using a liquid nitrogen-cooled $\mathrm{HgCdTe}$ narrow-band detector, and grazing incidence angle $\left(80^{\circ}\right)$ reflection geometry. The specimen used was a chemisorbed polymer film which was chemisorbed onto both aminosilane treated $\mathrm{Si}$-wafer and $\mathrm{Si}$-wafer for $24 \mathrm{~h}$ and annealed at $393 \mathrm{~K}$ for $8 \mathrm{~h}$, followed with solvent extraction to remove the unbound polymer.

The film thickness were measured by the optical ellipsometer (JASCO M-150) at an incident angle of 55 degree with He-Ne laser $(\lambda=632.8 \mathrm{~nm})$.

The surface chemical composition of the PSCOOH and the $\alpha, \omega-\mathrm{PS}(\mathrm{COOH})_{2}$ spin-coated films onto native oxide $\mathrm{Si}$-wafer were determined on the basis of X-ray photoelectron spectroscopy (XPS). The XPS spectra were obtained with ESCA 850 (Shimadzu Co., Ltd.) at room temperature with $\mathrm{Mg} K_{\alpha} \mathrm{X}$-ray source. The emission angle of photoelectron was 30 degree and therefore, the magnitude of the analytical depth from the outermost surface was $c a .4 .5 \mathrm{~nm}$.

In order to investigate the surface molecular motion of the end-functionalized PS films, LFM measurements were carried out at $293 \mathrm{~K}$ in air under a repulsive force of $c a .5 \mathrm{nN}$ and the lateral force was measured under the scanning rate of $10^{2}-10^{5} \mathrm{~nm} \mathrm{~s}^{-1}$. The LFM equipment used in this study was SPA 300 (Seiko Instruments Industry Co., Ltd.) with an SPI 3700 controller. A
Table I. The physicochemical properties of proton terminated PSs and carboxyl-terminated PSs

\begin{tabular}{crccc}
\hline & $M_{n}$ & $M_{w} / M_{n}$ & $2 R_{\mathrm{g}}{ }^{\mathrm{a}} / \mathrm{nm}$ & $T_{\mathrm{g}} / \mathrm{K}$ \\
\hline PS-H & $19.7 \mathrm{k}$ & 1.08 & 7.6 & 364 \\
PSCOOH & $9.7 \mathrm{k}$ & 1.18 & 6.0 & 375 \\
$\alpha, \omega-\mathrm{PS}(\mathrm{COOH})_{2}$ & $12.0 \mathrm{k}$ & 1.08 & 6.1 & 383 \\
PS-H & $40.4 \mathrm{k}$ & 1.08 & 11.1 & 368 \\
PSCOOH & $45.9 \mathrm{k}$ & 1.05 & 11.7 & 379 \\
$\alpha, \omega-\mathrm{PS}(\mathrm{COOH})_{2}$ & $51.7 \mathrm{k}$ & 1.08 & 12.5 & 386 \\
\hline
\end{tabular}

${ }^{a}$ Radius of gyration.

commercially available silicon nitride $\left(\mathrm{Si}_{3} \mathrm{~N}_{4}\right)$ integrated tips (Olympus Co., Ltd.) was used. The nominal spring constant of the cantilever was $0.09 \mathrm{~N} \mathrm{~m}^{-1}$.

\section{RESULTS AND DISCUSSION}

\section{Bulk Characterization}

The physicochemical properties of polystyrenes used in this study were summarized in Table I. Even though those polymers had the almost comparable $M_{n}$, the magnitude of $T_{\mathrm{g}}$ was in the order of PS-H $<$ PS-COOH $<$ $\alpha, \omega$-PS- $(\mathrm{COOH})_{2}$. The temperature at the midpoint of a base line shift in a DSC curve was defined as $T_{\mathrm{g}}$. Table I indicates that $T_{\mathrm{g}}$ 's of the carboxyl terminated PSs were higher than those of proton-terminated ones due to a decrease in chain end mobility and/or an increase in apparent molecular weight resulting from chain end association corresponding to the formation of hydrogen bonding among carboxyl end groups.

\section{Scanning Rate Dependence of Lateral Force}

In order to investigate the effect of chain end group on thermal molecular motion of the end-functionalized PS ultrathin films with thicknesses of $23-25 \mathrm{~nm}$ prepared onto different substrates, LFM measurements were carried out at $293 \mathrm{~K}$. Figure 1(a) shows the schematic representation of the frequency dependence of dynamic loss modulus, $E^{\prime \prime}$ for polymeric solids. In the case of very higher and lower frequency ranges in comparison with a relaxation frequency range, the polymer film is in a glassy state and in a rubbery one, respectively and shows a low magnitude of $E^{\prime \prime}$. On the other hand, in a relaxation frequency region, the polymer film is in a glass-rubber transition state and then, exhibits the maximum of $E^{\prime \prime}$. As discussed in our previous paper, the scanning rate dependence of frictional force showed a similar trend with the frequency dependence of bulk $E^{\prime \prime}$ as shown in Figure 1(b). ${ }^{10}$ Also, Gosch reported that the rate dependence of sliding frictional force exhibited the peak in a corresponding relaxation region to $T_{\mathrm{g}}{ }^{15}$ Takemura et al. showed that the magnitude of frictional force was almost proportional to the loss modulus, $E^{\prime \prime}$ based on the result of frictional experiment. ${ }^{16}$ These results apparently indicate that the frequency dependence of the $E^{\prime \prime}$ shown in Figure 1(a) might correspond to the scanning rate dependence of the frictional force shown in Figure 1(b). Therefore, it can be concluded from Figure 1 that there are the scanning rate independence of lateral force in a glassy or a rubbery state and also, the remarkable scanning rate dependence of lateral force in 

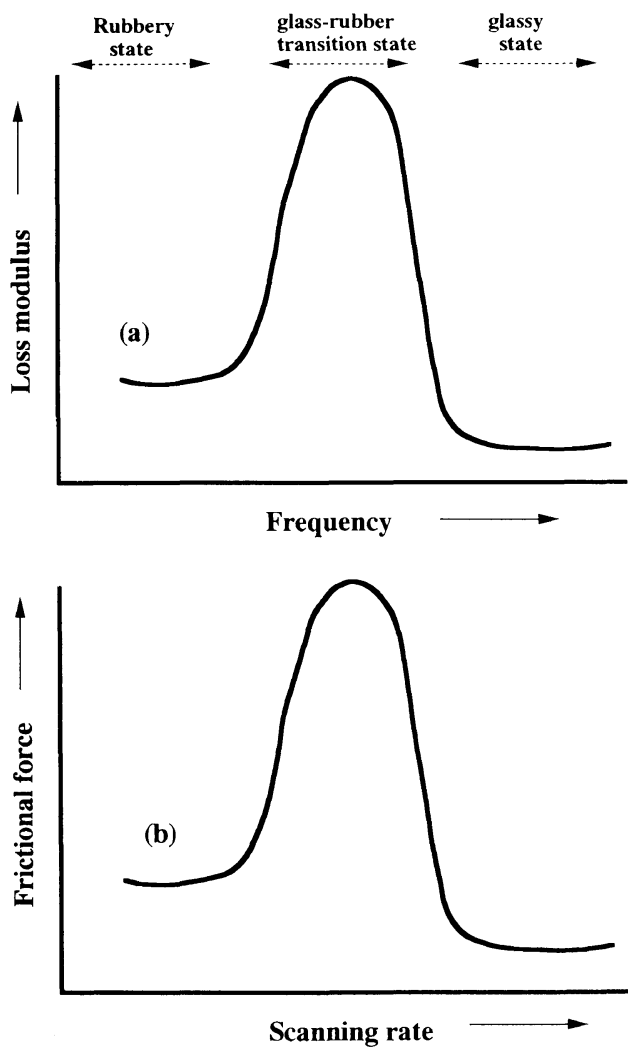

Figure 1. Schematic representation of the frequency dependence of dynamic loss modulus $E^{\prime \prime}$ and scanning rate dependence of lateral force.

a glass-rubber transition state.

Figure 2 shows the plots of lateral force against scanning rate for $\mathrm{PS}-\mathrm{H}$ with $M_{n}=19.7 \mathrm{k}$ and $40.4 \mathrm{k}$ spin-coated onto $\mathrm{Si}$-wafer before and after annealing treatments at $393 \mathrm{~K}$ for $8 \mathrm{~h}$. Since the magnitude of lateral force for the PS-H films (19.7k) was remarkably scanning rate dependent, this indicates that the surface of the as-spun PS-H films (19.7k) is in a glass-rubber transition state at $293 \mathrm{~K}$, even though the bulk $T_{\mathrm{g}}$ is far above $293 \mathrm{~K}$ as shown in Table I. Also, in the case of the as-spun PS-H film (40.4k), the scanning rate dependence of lateral force was not observed in a high scanning rate region but that was done in a low scanning rate region. Therefore, Figure 2 clearly indicates that the surface of as-spun PS-H film with $M_{n} 40.4 \mathrm{k}$ is in a glass-rubber transition state in a low scanning rate region and a glassy one in a high scanning rate region. As shown in Figure 2, the magnitude of lateral force for the annealed PS-Hs $(19.7 \mathrm{k}, 40.4 \mathrm{k})$ became more strongly dependent on the scanning rate in comparison with the as-spun PS-Hs, that is, the annealed PS-Hs $(19.7 \mathrm{k}, 40.4 \mathrm{k})$ were in a glass-rubber transition state over a whole range of scanning rate studied here. The annealing effect on the scanning rate dependence of lateral force indicated that the chain end groups of PS-H $(19.7 \mathrm{k}, 40.4 \mathrm{k})$ were preferentially segregated to the surface due to its lower surface free energy in comparison with that of the main chain part and then, an excess free volume was induced at the surface by chain end terminus. ${ }^{10}$

In order to investigate the effect of functionality of three types of end-functionalized PS and two kind of substrates on the surface molecular motion PS ultrathin films, the carboxyl-terminated PSs were used. Figure 3

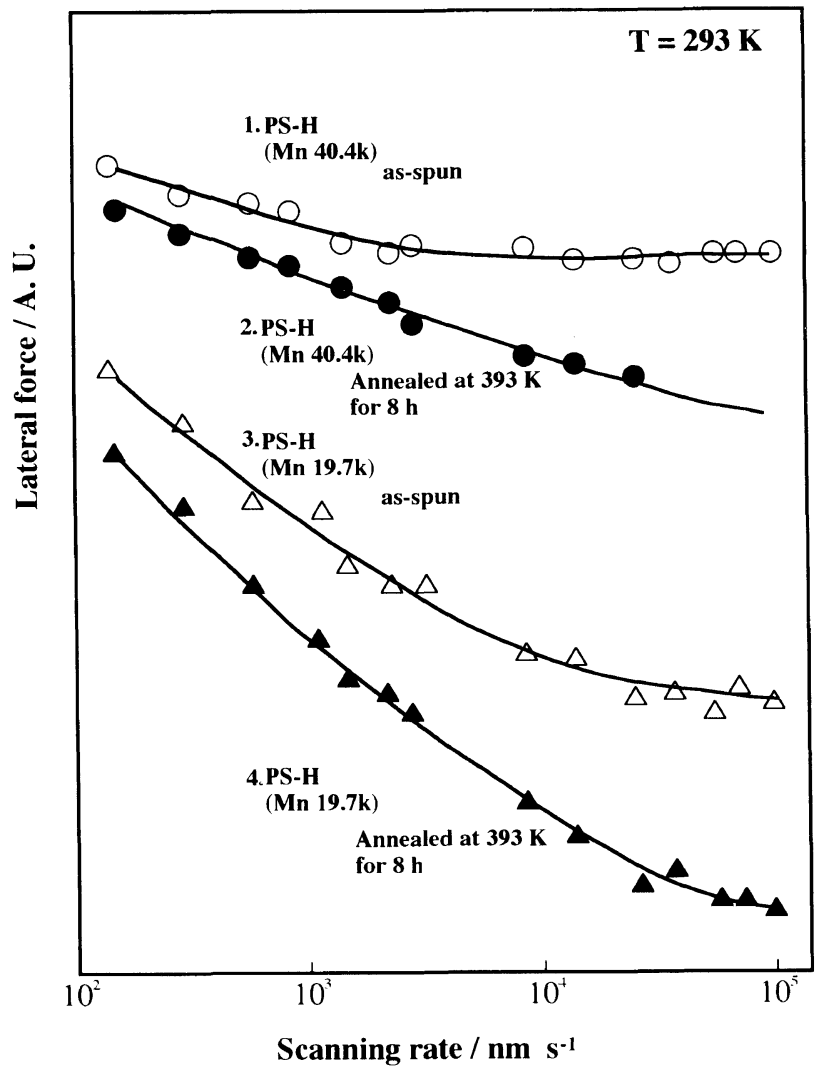

Figure 2. Scanning rate dependence of lateral force at $293 \mathrm{~K}$ for proton-terminated polystyrene, PS-H with various number-average molecular weight $M_{n}$ spin-coated onto Si-wafer before and after annealig at $393 \mathrm{~K}$ for $8 \mathrm{~h}$.

shows the scanning rate dependence of lateral force for PSCOOH and $\alpha, \omega-\mathrm{PS}(\mathrm{COOH})_{2}$ spin-coated on the $\mathrm{Si}$-wafer before and after annealing at $393 \mathrm{~K}$ for $8 \mathrm{~h}$. In the case of the as-spun PSCOOH film $(9.7 \mathrm{k}, 45.9 \mathrm{k})$, the scanning rate dependence of lateral force was fairly apparent in a lower scanning rate region at $293 \mathrm{~K}$, while this was not clearly observed in a higher scanning rate region. This result means that the as-spun $\mathrm{PSCOOH}$ (9.7k) exhibited both a glass-rubber transition state at the lower scanning rate region and also a glassy one at the higher scanning rate region. On the other hand in the case of the as-spun $\alpha, \omega-\mathrm{PS}(\mathrm{COOH})_{2}$ film $(12.0 \mathrm{k}$, $51.7 \mathrm{k}$ ), no distinct scanning rate dependence of lateral force was observed over a whole range of scanning rate as shown in the upper part of Figure 3. This indicates that the surface molecular motion was depressed due to a decrease of surface chain end group density with an increase in $M_{n}$.

It is appeared from the scanning rate dependence of lateral force shown in Figures 2 and 3 that the activation of surface molecular motion for the PSCOOH and the $\alpha, \omega$-PS $(\mathrm{COOH})_{2}$ on Si-wafer was depressed in comparison with that of the PS-H. Since in the case of $\alpha, \omega$ $\mathrm{PS}(\mathrm{COOH})_{2}$ the chain end groups of $\alpha, \omega-\mathrm{PS}(\mathrm{COOH})_{2}$ has higher surface free energy in comparison with that of the main chain part, the chain end groups might be preferentially depleted from the surface region, resulting in a less fraction of excess surface free volume in comparison with that of the PS-H with corresponding $M_{n}$. Also, since the $\alpha, \omega-\mathrm{PS}(\mathrm{COOH})_{2}$ end groups are intermolecularly associated by hydrogen bonding, an 


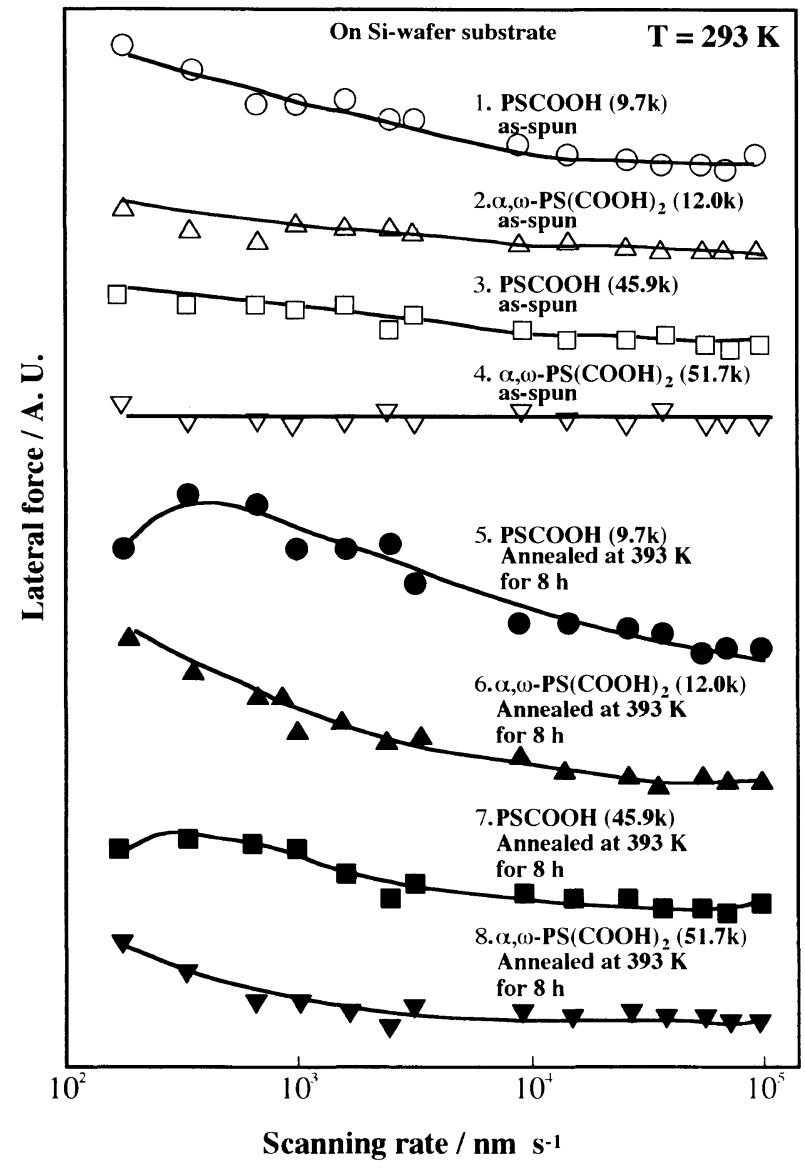

Figure 3. Scanning rate dependence of lateral force at $293 \mathrm{~K}$ for carboxyl-terminated polystyrene with various number-average molecular weight, $M_{n}$ spin-coated onto Si-wafer before and after annealing at $393 \mathrm{~K}$ for $8 \mathrm{~h}$.

apparent molecular weight of $\alpha, \omega-\mathrm{PS}(\mathrm{COOH})_{2}(12.0 \mathrm{k}$, $51.7 \mathrm{k})$ increases, resulting in an apparent decrease in the chain end group concentration as discussed later. Thus it seems reasonable to consider that the surface thermal molecular motion of $\alpha, \omega$-PS $(\mathrm{COOH})_{2}$ was remarkably depressed in comparison with that of PS-H with corresponding $M_{n}$ and then, was in a glassy state over a whole range of scanning rate studied here at $293 \mathrm{~K}$.

Since an anchoring of chain end groups to the substrate would influence the polymer chain mobility especially in the case of an ultrathin film, it might be interesting to investigate the annealing effect on the chain mobility of the PSCOOH and the $\alpha, \omega$-PS $(\mathrm{COOH})_{2}$ films above bulk $T_{\mathrm{g}}$. The lower part of Figure 3 shows the scanning rate dependence of lateral force of the PSCOOH (9.7k, 45.9k) and $\alpha, \omega$-PS $(\mathrm{COOH})_{2}(12.0 \mathrm{k}, 51.7 \mathrm{k})$ thin films on Si-wafer after annealing at $393 \mathrm{~K}$ for $8 \mathrm{~h}$. The enhanced scanning rate dependence of lateral force was observed for all samples of the PSCOOH $(9.7 \mathrm{k}, 45.9 \mathrm{k})$ and the $\alpha, \omega$ $\mathrm{PS}(\mathrm{COOH})_{2}(12.0 \mathrm{k}, 51.7 \mathrm{k})$, in comparison with that for the corresponding as-spun ultrathin films. The surfaces of the PSCOOH (9.7k) and the $\alpha, \omega-\mathrm{PS}(\mathrm{COOH})_{2}(12.0 \mathrm{k})$ are in a glass-rubber transition state, even though the bulk $T_{\mathrm{g}}$ evaluated by DSC were far above $293 \mathrm{~K}$ as shown in Table I. Also, the surfaces for the PSCOOH $(45.9 \mathrm{k})$ and the $\alpha, \omega-\mathrm{PS}(\mathrm{COOH})_{2}(51.7 \mathrm{k})$ were almost in a glass-rubber transition state except for a higher
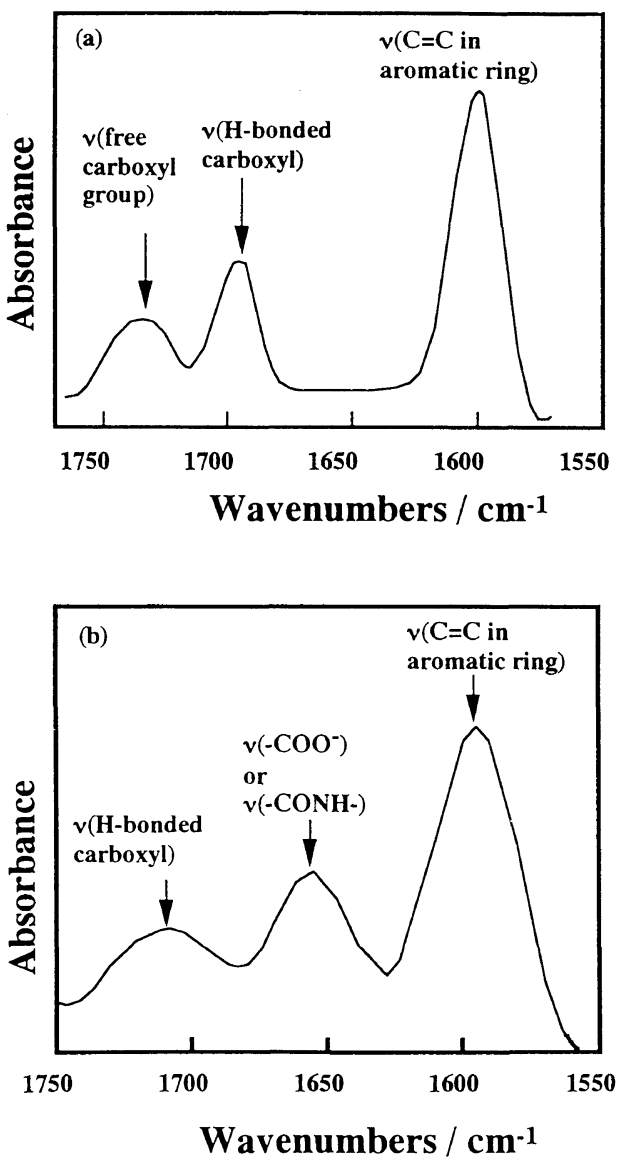

Figure 4. FT-IR-ERS spectra of $\alpha, \omega$-PS(COOH $)_{2}$ films on (a) Siwafer and (b) aminosilane-treated Si-wafer after annealing.

scanning rate region. The enhanced surface thermal molecular motion by an annealing treatment of these carboxyl-terminated PSs might be explained in terms of the interfacial interaction between $-\mathrm{COOH}$ ends and $\mathrm{HO}-\mathrm{Si}$ groups of the substrate. It is reasonable to consider that the weakening of interaction between $-\mathrm{COOH}$ and $\mathrm{HO}-\mathrm{Si}$ at an elevated annealing temperature might cause a rearrangement of the carboxyl-terminated PS chains, due to a recovery of conformational entropy resulting in a remarkable activation of the surface thermal molecular motion.

In order to confirm an intermolecular association of the carboxyl end groups, DSC and IR measurements were carried out. Since the bulk $T_{\mathrm{g}}$ of $\alpha, \omega-\mathrm{PS}(\mathrm{COOH})_{2}(12.0 \mathrm{k})$ was higher than that of PS-H (19.7k) as shown in Table I, it seems reasonable to consider that the apparent $M_{n}$ of $\alpha, \omega-\mathrm{PS}(\mathrm{COOH})_{2}(12.0 \mathrm{k})$ chain increases due to the intermolecular association, in other word, an apparent decrease in a chain end group concentration occured.

In order to reveal the difference in interaction between $-\mathrm{COOH} \cdot \mathrm{NH}_{2}$ and $-\mathrm{COOH} \cdot \mathrm{HO}-\mathrm{Si}$, the polymer chemisorbed onto the aminosilane-treated $\mathrm{Si}$-wafer was used. Figure 4 shows the FT-IR-ERS spectra of the $\alpha, \omega-\mathrm{PS}(\mathrm{COOH})_{2}(12.0 \mathrm{k})$ films on (a) the Si-wafer and on (b) the aminosilane-treated Si-wafer (b) at $293 \mathrm{~K}$. The spectrum of $\alpha, \omega$-PS $(\mathrm{COOH})_{2}$ on Si-wafer showed two absorption peaks at $1700 \mathrm{~cm}^{-1}$ and $1740 \mathrm{~cm}^{-1}$ corresponding to the stretching vibration of hydrogen bonded and free carbonyl groups, respectively. ${ }^{20}$ While the spectrum of $\alpha, \omega$-PS $(\mathrm{COOH})_{2}$ on aminosilane-treated $\mathrm{Si}$ - 


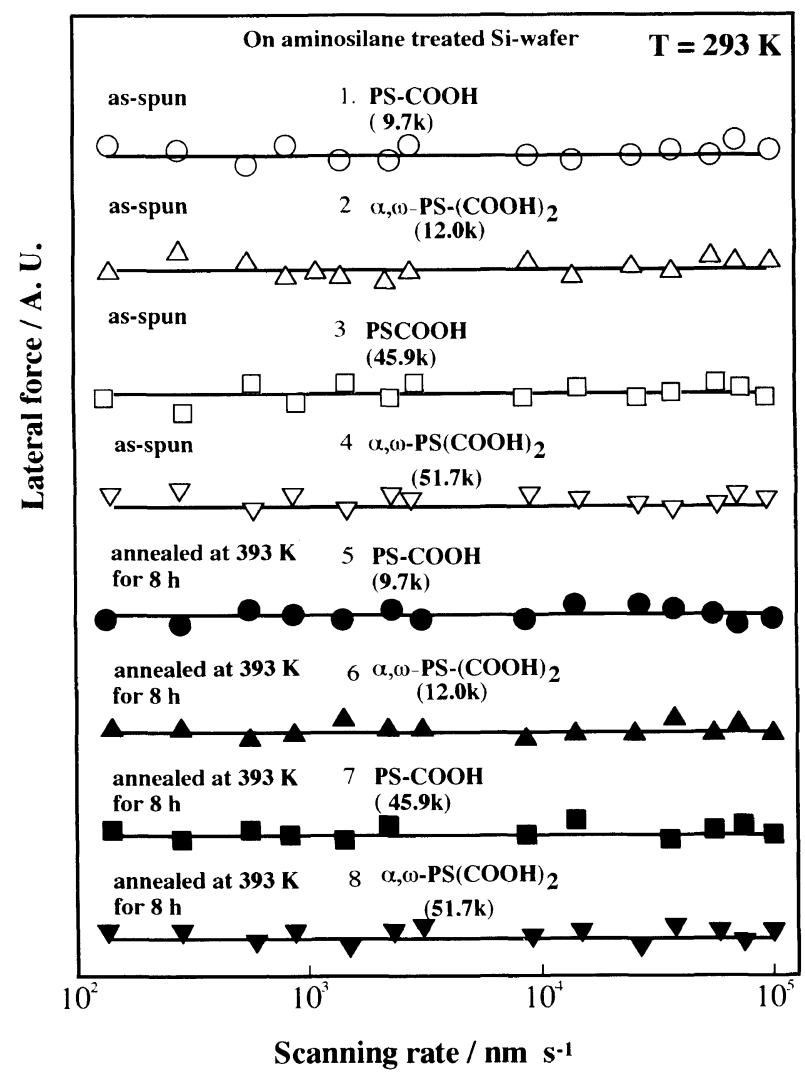

Figure 5. Scanning rate dependence of lateral force at $293 \mathrm{~K}$ for carboxyl-terminated polystyrene with various number-average molecular weight, $M_{n}$ spin-coated onto aminosilance treated Si-wafer before and after annealing at $393 \mathrm{~K}$ for $8 \mathrm{~h}$.

wafer shows the absorption peak at $1660 \mathrm{~cm}^{-1}$ corresponding to the stretching vibration of amide linkage. Figure 4(a) shows that a fairly large fraction of carbonyl groups formed by an intermolecular association between $-\mathrm{COOH}$ end groups. While Figure 4(b) shows that a stronger interaction between $-\mathrm{COOH}$ groups and $-\mathrm{NH}_{2}$ groups of aminosilane to form amide linkage, this might decrease chain end concentration and suppressed surface molecular motion of PS. Therefore, it can be concluded from DSC and FT-IR (Figure 4a) results mentioned above that an intermolecular association between $-\mathrm{COOH}$ chain end groups increased the bulk $T_{\mathrm{g}}$ in comparison with the $T_{\mathrm{g}}$ of PS-H and also, the surface thermal molecular motion for the PSCOOH and the $\alpha, \omega$-PS(COOH $)_{2}$ was clearly depressed in comparison with that of PS-H with the corresponding $M_{n}$. On the other hand Figure 4(b) indicates that the $\mathrm{NH}_{2}$ groups of aminosilane-treated $\mathrm{Si}$-wafer can form stronger hydrogen bonding with $-\mathrm{COOH}$ end groups of polymer than that between $-\mathrm{COOH}$ and $-\mathrm{Si}-\mathrm{OH}$ of Si-wafer substrate.

In order to investigate the effect of substrate-polymer interaction with respect to the surface thermal molecular motion, the aminosilane-treated $\mathrm{Si}$-wafer was employed as the substrate. Figure 5 shows the scanning rate dependence of lateral force for as-spun and annealed carboxyl-terminated PS ultrathin films onto spin-coated aminosilane-treated $\mathrm{Si}$-wafer. In the case that the aminosilane-treated Si-wafer was used as substrate, the scanning rate dependence of lateral force was not observed for the PSCOOH $(9.7 \mathrm{k}, 45.9 \mathrm{k})$ and the $\alpha, \omega$ -
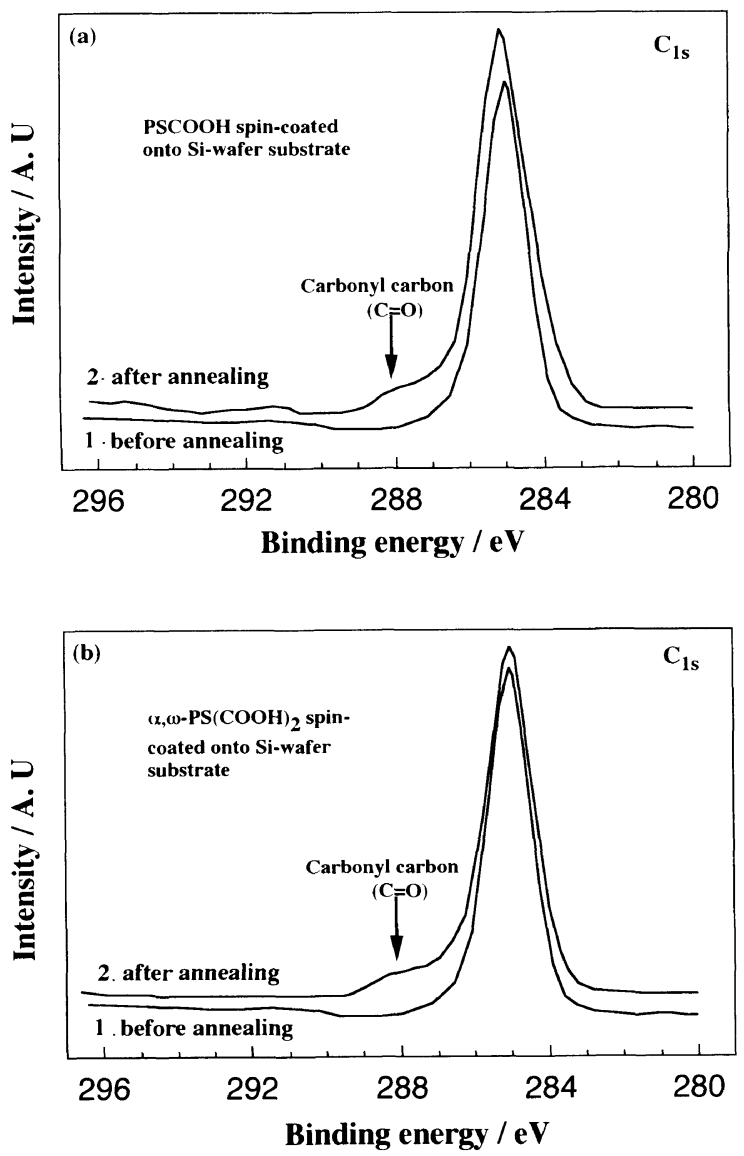

Figure 6. XPS $\mathrm{C}_{1 \mathrm{~s}}$ spectra of (a) PSCOOH and (b) $\alpha, \omega-\mathrm{PS}(\mathrm{COOH})_{2}$ spin-coated onto Si-wafer before and after annealing at $393 \mathrm{~K}$ for $8 \mathrm{~h}$.

$\mathrm{PS}(\mathrm{COOH})_{2}(12.0 \mathrm{k}, 51.7 \mathrm{k})$ ultrathin films, even though they were annealed at $393 \mathrm{~K}$ above bulk $T_{\mathrm{g}}$. Then Figure 5 clearly indicates that the surface of PSCOOH $(9.7 \mathrm{k}, 45.9 \mathrm{k})$ and $\alpha, \omega-\mathrm{PS}(\mathrm{COOH})_{2}(12.0 \mathrm{k}, 51.7 \mathrm{k}) \mathrm{spin}-$ coated onto aminosilane-treated Si-wafer were in a glassy state regardless of functionality, $M_{n}$ and annealing treatment. It seems reasonable to consider that the $\mathrm{NH}_{2}$ groups of ABDMS can form stronger hydrogen bonding with $-\mathrm{COOH}$ chain end groups of the polymer, than that between $-\mathrm{COOH}$ and $-\mathrm{Si}-\mathrm{OH}$. The stronger interaction between $-\mathrm{COOH}$ chain end groups of the polymer and $\mathrm{NH}_{2}$ groups of the aminosilane-treated Si-wafer might effectively reduce surface thermal molecular motion due to a decrease in excess free volume at the film surface.

In order to confirm the rearrangement of chain conformation of PSCOOH and $\alpha, \omega-\mathrm{PS}(\mathrm{COOH})_{2}$ on Siwafer and aminosilane-treated Si-wafer upon annealing, XPS spectra of the PSCOOH and the $\alpha, \omega$-PS$(\mathrm{COOH})_{2}$ spin-coated onto Si-wafer and aminosilanetreated $\mathrm{Si}$-wafer before and after the annealing treatment with an emission angle of 30 degree were obtained. Figure 6(a) and (b) shows the XPS $\mathrm{C}_{1 \mathrm{~s}}$ spectra for the PSCOOH $(9.7 \mathrm{k})$ (a) and the $\alpha, \omega$-PS $(\mathrm{COOH})_{2}$ (b) spin-coated onto $\mathrm{Si}$-wafer before and after annealing at $393 \mathrm{~K}$ for $8 \mathrm{~h}$. The neutral carbon $\left(-\mathrm{C}-\mathrm{C}^{*}-\right.$ ) was observed at $285.0 \mathrm{eV}$, and the shake-up peak corresponding to $\pi-\pi^{*}$ transition of benzene ring was observed at $291.5-292.0 \mathrm{eV}$. In the case of the as-spun PSCOOH and the $\alpha, \omega-\mathrm{PS}(\mathrm{COOH})_{2}$, $(-\mathrm{C}=\mathrm{O})$ did not appear at $288.5 \mathrm{eV}$. This might attributed to that the carboxyl end groups were de- 

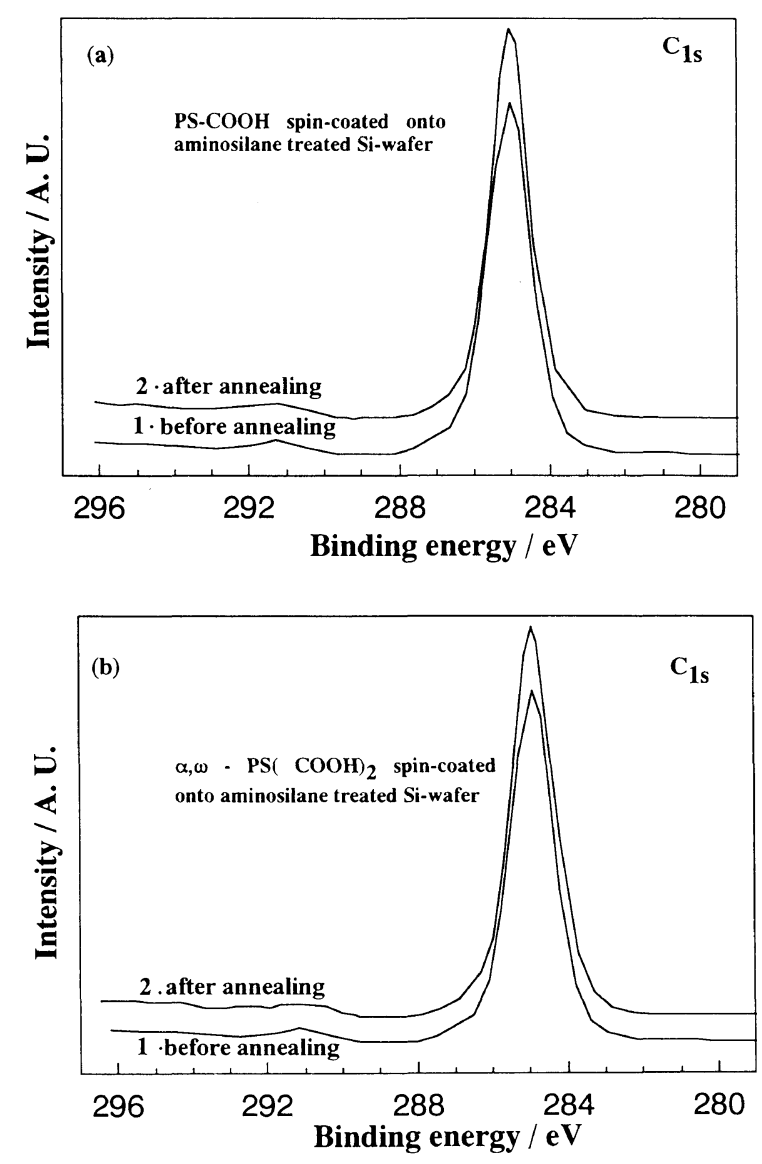

Figure 7. $\mathrm{XPS} \mathrm{C}_{1 \mathrm{~s}}$ spectra of (A) $\mathrm{PSCOOH}$ and (b) $\alpha, \omega$-PS(COOH $)_{2}$ spin-coated onto aminosilane-treated Si-wafer before and after annealing at $393 \mathrm{~K}$ for $8 \mathrm{~h}$.

pleted from the surface region and the intermolecular hydrogen bonding association of polymer chain was formed causing no excess chain end at the surface. Then, the scanning rate dependence of lateral force was not clearly observed. While in the case of annealed ones, the shoulder of $\mathrm{C}_{1 \mathrm{~s}}$ peak assigned to carbonyl group $(-\mathrm{C}=\mathrm{O})$ appeared at $288.5 \mathrm{eV}$. These results indicate that the weakening of the interfacial interaction between - $\mathrm{COOH}$ and $\mathrm{HO}-\mathrm{Si}$ linkage on Si-wafer substrate causes a conformational rearrangement due to recovery of its conformational entropy and then the chain end concentration increases slightly at the surface. This might explain why lateral force decrease with an increase in the scanning rate in the case of the PSCOOH and the $\alpha, \omega$-PS $(\mathrm{COOH})_{2}$ after annealing above the bulk $T_{\mathrm{g}}$. In contrast, Figures 7 (a) and (b) shows XPS $\mathrm{C}_{1 \mathrm{~s}}$ spectra of PSCOOH (9.7k) (a), and $\alpha, \omega-\mathrm{PS}(\mathrm{COOH})_{2}$ (b) spin-coated onto aminosilane-treated $\mathrm{Si}$-wafer before and after annealing at $393 \mathrm{~K}$ for $8 \mathrm{~h}$. The neutral carbon $\left(-\mathrm{C}-\mathrm{C}^{*-}\right)$ was observed at $285.0 \mathrm{eV}$, and shake-up peak corresponding to $\pi-\pi^{*}$ transition of benzene ring was observed at $291.5-292.0 \mathrm{eV}$. The carbonyl group $(-\mathrm{C}=\mathrm{O})$ was absent at $288.5 \mathrm{eV}$ region for as-spun PSCOOH and $\alpha, \omega$-PS(COOH $)_{2}$ and also for annealed ones. This was attributed to a stronger interaction between - $\mathrm{COOH}$ group of PS and $\mathrm{NH}_{2}$ group of aminosilane and depletion of end groups from the surface. Therefore, these results indicate that the both surface thermal molecular motion and the rearrangement of chain end groups effectively decreased with an increase in polymer-substrate interaction.

\section{CONCLUSION}

An effect of chain end group-substrate interaction on surface molecular motion of monocarboxyl- and dicarboxyl-terminated PSs and proton-terminated PSs with different number-average molecular weight, $M_{n}$ was investigated on the basis of LFM measurements. It was found that at room temperature and even after annealing upon bulk glass transition temperature of PS, the surface of the monodisperse PS-H $(19.7 \mathrm{k}, 40.4 \mathrm{k})$ was in a glass-rubber state due to an excess free volume at the air/polymer interface induced by the surface segregation of chain end groups due to the absence of interaction between PS-H and Si-wafer substrate. On the other hand, upon annealing, the surface of carboxyl-terminated PS ultrathin films on Si-wafer was in a glass-rubber transition state probably due to weakening of interaction between $-\mathrm{COOH}$ and $\mathrm{Si}-\mathrm{OH}$ which enhances the thermal molecular motion of PS.

In contrast, the monocarboxyl- and the dicarboxylterminated PSs spin-coated onto aminosilane-treated Si-wafer did not show any change in the lateral force regardless of functionality, $M_{n}$, and annealing treatment. It might be concluded that the specific interaction between $-\mathrm{COOH}$ of PS and $-\mathrm{NH}_{2}$ of aminosilanetreated $\mathrm{Si}$-wafer occured, resulting in a decrease in the chain end group concentration and the surface of PS ultrathin film became in a glassy state. These results indicate that the surface molecular motion could be effectively suppressed with an increase in end groupsubstrate interaction.

\section{REFERENCES}

1. W. J. Feast, H. S. Munro, and R. W. Richards, "Polymer Surface and Interfaces," Vol. 2, Wiley, New York, N. Y., 1993, Chapter III.

2. F. Garbassi, M. Morra, and E. Occhiello, "Polymer Surface from Physics to Technology," Wiley, New York, N. Y., 1994.

3. E. Rossler and H. Sillescu, 'Organic Glasses and Polymers,' in "Glassses and Amorphous Materials," Wiley, New York, N. Y., 1991, p 573.

4. J. L. Keddie, R. A. L. Jones, and R. A. Coury, Europhys. Lett., 27, 59 (1994).

5. G. B. DeMaggio, W. E. Frieze, D. W. Gidley, M. Zhu, H. A. Hirstov, and A. F. Yee, Phys. Rev. Lett., 78, 1524 (1997).

6. J. A. Forrest, K. Dalnoki-Veress, J. R. Steven, and J. R. Dutcher, Phys. Rev. Lett., 77, 2002 (1996).

7. T. Kajiyama, K. Tanaka, I. Ohki, S. R. Ge, J. S. Yoon, and A. Takahara, Macromolecules, 27, 7932 (1994).

8. T. Kajiyama, K. Tanaka, and A. Takahara, Macromolecules, 28, 3482 (1995).

9. K. Tanaka, A. Takahara, and T. Kajiyama, Acta Polymer, 46, 476 (1995).

10. K. Tanaka, A. Takahara, and T. Kajiyama, Macromolecules, 30, 280 (1997).

11. K. Tanaka, A. Takahara, and T. Kajiyama, Macromolecules, 30, 6626 (1997).

12. K. Tanaka, A. Takahara, and T. Kajiyama, Macromolocules, 31, 863 (1998).

13. R. M. Overney, E. Meyer, J. Formerm, D. Brodbeck, L. Howald, H. Guntherodt, M. Fujihira, H. Takano, and Y. Gotoh, Nature, 359, 133 (1992).

14. R. M. Overney, E. Meyer, J. Frommer, H. J. Guntherodt, M. Fujihira, H.Takano, and Y. Gotoh, Langmuir, 10, 1281 (1994). 


\section{E. S. A. Mounir, A. Takahara, and T. Kajiyama}

15. K. A. Gosch, Proc. R. Soc. London, Ser. A, 274, 21 (1963).

16. K. Minato and T. Takemura, Jpn. J. Appl. Phys., 6, 719(1967).

17. G. Haugstad, W. L. Gladfelter, E. B. Weberg, R. T. Weberg, and

R. R. Jones, Langmuir, 11, 3473 (1995)

18. E. A. Mounir, A. Takahara, and T. Kajiyama, Polym. J., 31, 89
(1999)

19. D. Bayer, T. M. Bohanon, W. Knoll, H. Ringsdorf, G. Elender, and E. Sackmann, Langmuir, 12, 2514 (1996).

20. J. F. Elman, B. D. Johs, T. E. Long, and J. T. Koberstein, Macromolecules, 27, 5341 (1994). 